Article

\title{
Spirituality and Wellbeing in the Context of a Study on Suicide Prevention in North India
}

\author{
Rekha Wagani ${ }^{1}$ and Erminia Colucci ${ }^{2, *}$ (i) \\ 1 Amity Institute of Behavioral and Allied Sciences, Amity University Mumbai, Mumbai-Pune Expressway, \\ Panvel, Mumbai, Maharashtra 410206, India; rwagani@mum.amity.edu \\ 2 Department of Psychology, Middlesex University London, The Borroughs, Townhall, London NW4 4BT, UK \\ * Correspondence: e.colucci@mdx.ac.uk; Tel.: +44-(0)20-8411-4363
}

Received: 22 March 2018; Accepted: 28 May 2018; Published: 7 June 2018

check for updates

\begin{abstract}
The connection between spirituality and wellbeing, including its benefits for physical and mental health, has been recognized in the Eastern cultures for a very long time, although the sharp division between science and religion has caused, for the most part, its neglect in Western cultures until recently. Nevertheless, limited efforts have been made to explore the impact of spirituality and religion on wellbeing, including the prevention of suicide. We begin with an overview of the literature on religiousness, spirituality, and health and wellbeing. Further, we present a novel study focused on a sample of 160 Indian students from a spiritually oriented university in North India with the aim to understand how spirituality affects their lives and wellbeing and their views about suicide. Our results show that spirituality, generally, has a positive impact on participants' wellbeing with a potential protective effect against suicidal behavior, although more research on spiritual/religious beliefs as a source of difficulties is warranted.
\end{abstract}

Keywords: spirituality; religion; spiritual wellbeing; suicide; suicidal behavior; meaning; India; youth

\section{Introduction}

Research has found that religiousness and spirituality are strongly linked to health and wellbeing (Büssing et al. 2014; King and Benson 2006; Colucci 2008), and in a variety of ways. A first potential mechanism of action linking religiousness/spirituality to health is via social networks (Hill and Butter 1995) as measured, for instance, through the level of religious commitment or attendance at religious events or services (George et al. 2009). Religious and spiritual communities can give people the opportunity to develop social relationships and enlarge their own social network. In turn, social support can have positive effects on health, such as reducing the impact of stress (House et al. 1998). Some authors (Musick et al. 2004) believe that it is the presence of a religious confidante to mediate this relation (e.g., personal relation with God, fellow parishioners, or clergy), while others think it is the effect of altruistic behaviors linked to religious worldviews, which help to extend one's social network (Oman et al. 1999).

A second way in which spirituality is recognized to be related to wellbeing is lifestyle. Religion may be the reason for someone to adopt a healthy lifestyle and to avoid unhealthy behaviors, given precepts about alcohol and drug consumption, sexual habits, and alimentation that are present in many world religions (Troyer 1988). Religion teaches us to take care of one's body, believing our body and health to be a gift from God, and a temple that must be preserved and respected (George et al. 2009).

A third mechanism through which spirituality and religion influences health is through psychological factors. These psychological factors are numerous and include various phenomena like cognitive, affective, self and identity, and socio-psychological (Hill et al. 2000). For instance, Pargament (1997) lists religious coping strategies that help in coping with negative life events, such as 
meditation, prayers, internal locus of control, and self-directing style. Other psychological factors such as self-esteem, auto-efficacy, and strength of will, which in some studies have been linked to religious commitment, are found to be associated with better health/mental health outcomes (Campbell 1999; Turner and Lloyd 1999).

Another important aspect that can be considered as a psychological mechanism that contributes to the link between spirituality and wellbeing is meaning in life or purposefulness (Hawks 1994; Wong and Fry 1998). A sense of meaning in life can give people higher levels of psychological and physical wellbeing (Reker 1994) and can be particularly important to preventing suicidal behavior (Colucci 2008, 2009a; Colucci and Martin 2008; Colucci and Lester 2013; Moreira-Almeida et al. 2006; Rasic et al. 2009). Marsella (1999) stated that the importance of spirituality is to provide a set of values and meanings to give order to the world, and to provide what Erikson [1850] (1963) called "a sense of coherence." Antonovsky (1980) believed that these ideas about one's life and the world can help people to withstand stressful situations. Similarly, Viktor Frankl (1959) emphasized the need to find a purpose in life to survive, and underlined how a religious or other belief system may be one pathway toward developing meaning and purposefulness in life, providing goals to achieve, values to respect, and rituals to follow.

Another important component of spirituality is the development of the spiritual identity of an individual and the incorporation of spirituality into a personal sense of self, which has also been viewed as linked with wellbeing (MacDonald 2009). Thus, spirituality can be seen as a journey that provides an individual with various goals, such as self-development, connectedness with God/the sacred, and development of specific values or practice of specific rituals as a medium to achieve larger goals. This process of goal orientation has been well explored in health literature and findings indicate its strong association with wellbeing (Sheldon et al. 2004), mental health, and suicide (Colucci 2008, 2009a, 2009b; Colucci and Lester 2013), particularly if the goals are constitutive and intrinsic by nature (Fowers et al. 2010; Ryan and Deci 2000), involve personal integration, and contribute to a sense of meaning and purpose (Ho et al. 2010).

Other authors analyzed religion in terms of giving people a complete vision of life. For example, Pargament (1997), Hood and collaborators (Hood et al. 2009), and Berger (1967) have referred to religion as a symbolic universe. A system of belief is particularly important in time of crisis, such as while facing suicidal thoughts, because it may provide a resource to understand the difficult situation and to accept tragic and stressful events (Idler et al. 2003), potentially transcending stressors.

In addition to studies that highlight a positive link between spirituality and wellbeing and health, there are a few others that suggest that spiritual/religious beliefs can be harmful in particular circumstances (Colucci 2008, 2009a; Colucci and Martin 2008). These include the use of negative religious coping, which can include delegation of solution of problems to a Higher Power (e.g., asking for direct divine action to solve problems); feeling that life experiences are part of God's larger plan, with no personal control over the situation; and beliefs that difficulties are a punishment from the deity or the devil (Pargament 2002; Fitchett et al. 1999).

As indicated by Büssing and collaborators (Büssing et al. 2014, p. 1), "the impact of a person's religiosity/spirituality on health is multifaceted and is fraught with methodological controversy since one has to deal with cognitive approaches (specific attitudes and beliefs), emotions, practices (spiritual/religious and secular forms), specific behaviors, reactive strategies to deal with illness (coping), and spirituality/religiosity-based interventions (i.e., meditation, mindfulness, and prayer). Because of this complexity, an interdisciplinary perspective is required for research as well as clinical care."

This study merges approaches from medical anthropology, clinical and community psychology, and cultural psychiatry with the aim to investigate how spirituality influences wellbeing and, potentially, suicidality among young Indians, reflecting a multidimensional understanding of spirituality (Colucci 2008; Hill and Hood 1999). This age group was chosen because of its higher risk for suicide (Colucci and Lester 2013). 


\section{Aims}

To date, efforts made to identify the links between spirituality, religion, and wellbeing and health, including mental health and suicide, have mainly relied on questionnaires, scales, and structured interviews (Colucci 2008; Colucci and Martin 2008; MacDonald and Friedman 2009). To fully understand this linkage, it is crucial to investigate, in-depth, a sample of people who are systematically exposed to spiritual concepts and practices. Below, we present a novel study focused on these interrelationships. In the present study, the sample was taken from a spiritually oriented university (Dev Sanskriti Vishwavidyalaya, DSVV) located in Haridwar in North India, at the foothills of the Himalayas, which is considered one of the holiest Hindu pilgrimage sites. At DSVV the students, regardless of the course they are enrolled in, receive classes and modules aimed at teaching philosophy and spiritual concepts and practices. The university inculcates these practices in two specific ways: Firstly, each student studies the theoretical background of spirituality and Indian value systems, and attends lectures from spiritual gurus, which are then assessed through evaluation at the term end of the program. Secondly, the same theories and philosophies are presented through applied forms, such as various kinds of meditation, performance of yajna (i.e., a ritual that involves a specific combination of herbs offered in fire with sacred chants), yoga, prayers, chanting of Sanskrit mantra (i.e., specific mantra with a prayer focus on everybody's wellbeing including oneself), as well as by practicing values such as simple living, minimum consumption of environmental resources, and taking active part in environmental cleaning and protection. The university also provides teaching materials to students that define or explain concepts of spirituality and religion using scientific knowledge and, pragmatically, as it applies to their day-to-day life. The schedule of activities is common for all students but they practice and adopt teachings according to their own capacity and priorities. The short documentary "Haridwar: A spiritual journey" (Colucci 2009b) illustrates some of the activities and practices the students undergo.

\section{Method}

The theoretical framework of this research, as for the previous research that inspired this study (Colucci and Lester 2013), is Phenomenology with a particular reference to two models: Symbolic Interactionism (Blumer 1969) and (Personal and Social) Constructivism (Berger and Luckmann 1966). Thus, the focus is on the personal and socio-cultural meanings participants attach to the world around them, particularly their spiritual world.

A qualitative methodology was selected for this study as it allows us to explore the embedded meaning of a construct like spirituality as well as to capture the contextual understanding of the relationship between spirituality and/or religion and wellbeing/mental health and suicide (Colucci and Martin 2008).

\subsection{Data Collection}

As the aim was to investigate how spirituality influences wellbeing, we used both qualitative and quantitative methods reflecting a multidimensional understanding of spirituality (Hill and Hood 1999). The data collection was divided into two stages:

1. The first stage was based on a self-administered survey composed of the WHOQOL (Quality of Life) Spirituality, Religiousness and Personal Beliefs (SRPB) Field-Test Instrument (WHO-SRPB), open questions on spirituality and religion, and a section on youth suicide (attitudes scale, open-ended questions, and questions on previous experience and exposure). These open-ended questions were taken from a linguistically adapted version of the WHO-SRPB instrument (WHOQOL SPRB Group 2002a, 2002b), which measures the importance of spiritual, religious, and personal beliefs in one's wellbeing. To try to find a definition of spirituality that could apply to the specific context of this spiritual community, we asked participants their own definition of spirituality. We also included questions to understand if, 
and how, spirituality influences the wellbeing of the participants and/or can be a source of difficulty in participants' lives, such as the following:

- Do your spiritual, religious, and personal beliefs contribute to your wellbeing? If so, please give some examples.

- Do your spiritual, religious, and personal beliefs help you to overcome life's difficulties? If so, please give some examples.

- Have there been instances in your life where your spiritual, religious, and personal beliefs have been a source of difficulty? If so, please give some examples.

One section of the questionnaire also included open-ended questions about youth suicide; questions about previous experience with, and exposure to, suicide; and a youth suicide attitude scale. These questions were taken from Colucci's study on the cultural meanings of suicide among Indian, Italian, and Australian young people (Colucci and Lester 2013).

2. The second stage involved recorded activity-based focus groups discussions (FGD) about religion/spirituality and suicide prevention with self-selected participants who had previously completed the questionnaire and had indicated, in the consent form, their willingness to also take part in focus groups. The objective of these was to investigate in greater depth if and how spirituality influences the life of the participants, which included activity-based and open-ended questions such as

- Do you have spiritual/religious beliefs? If so, describe your beliefs and say in which forms do you practice such beliefs.

- How important to you are your spiritual/religious beliefs?

Activity-based focus groups use creative ways and includes various exercises to generate responses from the participants to keep them engaged and motivated during the FGDs (Colucci 2007). Various methods like free listing, ratings, ranking, and pile sorting were used during the FGDs by the moderator to produce and enrich data.

\subsection{Translation}

The questionnaires were independently translated to Hindi from English by two bilingual psychology students, and then back-translated by two other students. The back-translated versions were compared and when differences were found by the team, one of the authors (RP) worked together with two translators to reach an agreement. Participants were given the possibility to use the Hindi or the English version of the survey and to answer in either of the two languages. Open-ended questions answered in Hindi were translated by RP. With the exception of one group with English-speaking participants, focus groups were held in Hindi and recordings were translated to English by RP.

\subsection{Sample}

Before data collection started, the study was approved by the DSVV committee. Students enrolled in different courses received the questionnaire together with the Plain Language Statement and consent form at the start of their class and our person in the class was asked to collect the questionnaires and return to the researcher after class. Of 327 questionnaires distributed, 160 were completed and the others were returned blank or only partially completed and were therefore eliminated. The final sample was equally distributed by gender $(\mathrm{M}=82, \mathrm{~F}=78)$ and aged between 17 and 25 years $(\mathrm{M}=20.96)$. All participants were at least second-generation Indians (i.e., born in India, with both parents born in India), and most of them were single (89.4\%) and with a middle-low (44.4\%) or middle-high $(38.1 \%)$ socio-economic status. Most participants indicated that their religious affiliation was Hinduism $(86.2 \%)$ and that they were born and raised in a religious tradition $(81.9 \%)$ and to currently practice the same religion $(76.2 \%)$.

For the focus group part, we moderated four groups with 10-11 persons each (total 42), who met for two 1.5-2 h long sessions. One of the groups consisted of only male participants, one only females, 
and two groups were equally divided between the sexes, for a total of 20 females and 22 males, aged between 18 and 24 years $(M=19.85)$.

\subsection{Data Analysis}

In this article we only report qualitative data from Stages 1 and 2 of the research. The qualitative data collected was analyzed using thematic analysis, following the guidelines developed by Barun and Clarke (2006). This flexible approach yields rich and detailed accounts with embedded meanings and the context of the data, without applying theoretical lenses for interpretation. All the audio data and responses on open-ended questions were transcribed verbatim. The transcript was first filtered and organized according to various sections and subsections based on the questions. Initial coding was done to identify possible patterns in the data. After the initial coding, the data was organized in meaningful categories. A thematic map was drawn to visualize the whole data set in terms of the categories. The main themes/patterns were reanalyzed and finalized through deletion and merging of some themes in main themes (King 2004). The analyses were independently done by two researchers and reviewed for consistency by a third researcher. Refinement and organization of the themes was done to the extent that no new themes or ideas were left by the researchers in the data set (Creswell 2007).

\section{Results}

This section presents the key findings. Five primary themes were identified, which were subdivided into several subthemes (see Table 1).

Table 1. Key primary themes and subthemes

\begin{tabular}{ll}
\hline \multicolumn{1}{c}{ Primary Themes } & \multicolumn{1}{c}{ Subthemes } \\
Meaning of spirituality & $\begin{array}{l}\text { Spirituality is self-knowledge } \\
\text { Spirituality is integral to self-journey } \\
\text { Spirituality is connection with God }\end{array}$ \\
\hline \multirow{2}{*}{ Influence of spirituality } & $\begin{array}{l}\text { Positive emotions and feelings } \\
\text { Life goals } \\
\text { Towards selflessness from selfishness }\end{array}$ \\
\hline & $\begin{array}{l}\text { Through change in self } \\
\text { Through meaningfulness }\end{array}$ \\
& $\begin{array}{l}\text { Through spiritual techniques and practices } \\
\text { Faith and belief in the sacred } \\
\text { Attitude towards Life }\end{array}$ \\
\hline Difficulty on Spiritual Path & \\
\hline Suicide & Reasons for Suicide \\
& Signs before engaging in suicidal behavior \\
\hline
\end{tabular}

\subsection{Meaning of Spirituality}

Participants were asked about their subjective definition of the term "spirituality". They described the concept in many ways; however, three secondary themes emerged indicative of different understandings about spirituality.

\subsubsection{Spirituality is Self-Knowledge}

When asked "What do you mean by spirituality?", the most frequent category of answer was about the improvement and knowledge of oneself. Spirituality was often defined as a way to know oneself, the inner self, or the soul. Most of the participants agreed that spirituality helps one become self-aware and increases self-knowledge, whether it be values, potential, inner strength, abilities, or capacities. 
For example, one of the students said that for him, "Spirituality means to know about one's self" (Q23F). ${ }^{1}$ Other students indicated that to them "spirituality means to know myself" (FG1.1F4). ${ }^{2}$

Spirituality was also defined as a way to become aware about various dimensions of self, such as the following: "Spirituality means exploring your inner self, your abilities, capacities and potential in order to form a good personality" (Q2F). Spirituality was described as the science of inner knowledge, for instance, "Spirituality is knowledge about the inner world. As science gives us knowledge about the external world, like that, spirituality helps us to know and understand our inner strengths" (Q37F). Other participants emphasized meanings and values as central in their understanding of spirituality, such as, "Getting to know your own inner values ... getting to know oneself is spirituality" (Q4F) or "Spirituality means that we know our existence, our motives, objectives of our life to come on this earth" (Q5M).

\subsubsection{Spirituality is Integral to Self-Journey}

For many participants, spirituality is not a static concept but rather a journey to reach the spiritual self, which may encompass self-knowledge as expressed for instance by this respondent: "To study one's own soul, to know it, and to push it higher is spirituality. Spirituality means the absorption of soul in the supreme" $(\mathrm{Q} 99 \mathrm{~F})$. Participants frequently mentioned that spirituality has become an integral part of their life journey as expressed by one participant: "spirituality can improve our knowledge of ourselves and attitude. I did not know what spirituality was. I started using it at age 12 and I have steadily improved myself" (FG4.1M7).

Thus, some participants perceived that spirituality generates awareness/knowledge of the self in an individual, which facilitates the journey of self-knowledge through the development of their potential: "Spirituality is knowledge by which we know about self. It grows the feeling of self-realization in a human" (Q13F). Some of the participants linked this personal journey of self-awareness with other people's development, as expressed by one of the respondents: "To be aware about myself. Each person has unlimited potential. After knowing the potential of our personality, we have to actively utilize it. Our potential should be used to elevate creativity andconstructivity to reduce the suffering of humanity." (Q23F). Some perceived it as a path: "If we walk the path of spirituality then we can achieve huge things ... We can develop personality" (FG1.1F4).

\subsubsection{Spirituality is Connection with God}

The participants used the term "God" and defined it as a symbol or group of highest ideals and values. For example, one of the participants specified that "humans and god are not different from each other, and good deeds and right feelings are representative of god" (Q327M). Some defined god as a supreme being, such as, "I think that the root aim of all the religions are to achieve that supreme state where initially od is worshipped in any form (forms have been described in Hindu mythology)however; that supreme is formless" (Q250F). For some, spirituality means connectedness with God; that is, to understand and to be close to God and to absorb God's qualities, as revealed by one of the respondents who stated, "Spirituality means to unite with God or become one with God" (Q16F). An establishment of a deeper connection with God in all kinds of circumstances (happy vs sad) was seen as a parameter to check how spiritual an individual is, as explained by this participant: "Spirituality means the study of soul, the study of self, the study which tells us how much we are near to God, how much capability we have to face the difficulties of life, how much we are near to God even in the difficulties of life, how we feel him in the pleasures of life, how much we know ourselves, and how deep our relationship is between God and us" (Q36F).

1 This code indicates that the quote was taken from Questionnaire 23, which was filled by a female participant.

2 FG indicates quotes derived from Focus Groups 1, Session 1, and F4 denotes that it was Participant 4 who was female. 


\subsection{Influence of Spirituality}

When asked if and how spiritual practices or spirituality influence their life, participants responded in varied ways; however, most of them endorsed a positive influence in terms of increased self-awareness, self-knowledge, increased sense of peace and happiness, and goal orientation. Participants specified that spirituality provides a bigger frame of reference, which in turn helps them to understand their position in this world.

\subsubsection{Positive Emotions and Feelings}

Participants frequently mentioned that spirituality had positive effects, such as they felt more optimistic, happy, and positive after practicing spirituality, for instance: "My life is highly influenced by spirituality. Now I feel myself as more optimistic and happy" (Q1F). Another participant said that "[i]t predisposes us to think positively" (Q29M). Some related it with happiness: "I remain very happy" (Q47F) or "now I have developed capacity and have become emotionally strong. I can be tired after running around all day but I have emotional strength to keep going. I have developed positivity" (FG1.1F5). Some participants also indicated that happiness is a choice of an individual and spirituality teaches a person to choose happiness over sadness through a positive attitude: "In life happiness and bad things come together; both are two sides of one coin. In this situation of sorrows and difficulties, spirituality gives us support and patience, and spirituality tells us about being positive" (Q62M).

Another frequent response was that spirituality gives inner peace and calmness, such as, "Now I am in this good environment, I felt this when I came here, and for the first time I feel inner peace in this holy environment" (Q9F).

Most of the participants mentioned terms like inner peace, hope, trust, positive thoughts, happiness, inspiration, encouragement, and determination. It seems that these positive constructs help them to experience positive emotions, which some of them described as the outcome of spiritual practices: "ever since I have adopted spirituality I have improved. I could not express my feelings about it, now I have learnt to turn my feelings. If I feel negative I turn it to positive ... I don't need to go to anyone for help, I can do it by myself" (FG1.1F8).

\subsubsection{Life Goals}

Most of the participants described the influence of spirituality on their life in terms of developing a clear goal or path in their life. During their narrations, various goals were cited by the participants, which can be categorized into two kinds of goals, that is, personal and social goals. The most consistent goals were related to development of self and to enriching their personal life as mentioned by one of the participants who stated, "To be satisfied about oneself, and to do one's best to do one's own duties, and become successful in one's profession or my professional life, believe in oneself, be kind, be a nice person." At the personal level, most of the participants linked their goals to achieving meaningfulness; for instance, they said "that clarity of goals increases meaningfulness in life". Spirituality was also seen as the reason to have some goals: "Due to spirituality, we have aim in life and feel meaningfulness for life" (Q51M).

For most of the participants, spirituality was seen as a way to develop a pathway toward growth and progress of oneself: "Spirituality and religion make our life finer and good, and life always goes on the pathway of growth" (Q58M). Spirituality was perceived as an important element of day-to-day life: "Spirituality and religion shows us a way to live life; therefore, it is clear that it affects our life in each step" (Q28F).

Participants consistently mentioned establishing a connection with God as an important goal of spiritual life, for example: "Spirituality means to go near to God" (Q52M) . Some other goals that were frequently mentioned were to continue the search of the truth, living according to human values and ideals (e.g., social justice, trueness, being detached from material goods), to know oneself and one's ability, and to improve oneself: "Spirituality affects our life from moment to moment. Spirituality 
and righteousness put us on an honest and good path" (Q29M). Some participants mentioned that their goals increase their self-esteem or self-respect. These goals help them to overcome the feeling of emptiness and give them a direction, as mentioned for instance by this participant: "When I get bored from my life and feel that there is nothing in my soul encouraging me to do my best, I realize that I am not an ordinary person, but I am strong, mentally and physically ( ... ). Spirituality helps me to find my goal" (Q84F). Participants believed that spirituality teaches the individual to work for the community and to empower society through their active actions and participation, as stated for example by this participant: "My goal is to open a school and orphanage and improve the life of children to make them better future citizens. This purpose makes me feel that my life is beautiful" (Q2F).

\subsubsection{Towards Selflessness from Selfishness}

For most participants, selflessness-in terms of expansion of their territory from self to others-was very evident. Participants specified that living for oneself is not sufficient; rather, spirituality teaches one to think about others, and to contribute in other's wellbeing and growth. As mentioned by a participant, "spirituality means enhancing your potential and becoming higher in thinking, and serving the whole of humanity" (FG1.1F3) or "[s]pirituality is useful only because it gives us belief in humanity; it has taught me to love all humans" (FG3.1F1). They mentioned that this selfless work should not include any kind of expectation towards the person who is receiving the help, such as the following: "In my life spirituality comes in the form of helping of others and service to needy persons, belief in God and helping people without having any expectations" (Q12F).

Some of the participants could relate their life aims to society as a whole. Some of them used the term "society," while others used "nation" and "world" specifically. As mentioned by one of the participants, "I donate my time for the welfare of nation and society, and do those works" (Q100M). Some participants specified that works for society may include helping others, spreading spirituality, and holding values such as brotherhood/sisterhood and awareness about spiritual practices. As one participant stated, "Yes, we will do work truthfully by increasing brotherhood, unity, homogeneity, and reducing gaps between persons through religious, spiritual and personal beliefs" (Q51M). Participants could connect their selfless work with feelings of satisfaction, meaningfulness, and completeness: "Whenever I help someone and they feel satisfied, this helps me and gives me self-respect, and it makes me think my life is completely meaningful for me and others too"(Q31F).

\subsection{Ways to Achieve Health and Wellbeing}

When participants were asked how spirituality impacts their wellbeing and health, they indicated four possible ways:

\subsubsection{Through Changes in Self}

Participants stated that spirituality introduced changes in their sense of self. They mentioned that spirituality refines their thinking, feelings, and action, and contributes to improving and developing oneself, such as the following: "In daily life I worship, meditate; if I hurt someone I reflect on why I did it ... I write a diary at night to see what mistakes I made and how can I improve myself" (FG1.1F9). Some expressed that they incorporated a new routine to develop their self "I do meditation at 6 p.m. so that I wake up at 3 a.m. to go for a walk, pray, then attend yagnya at 6 a.m., then attend college classes" (FG3.1F1).

\subsubsection{Through Meaningfulness}

Most of the participants described meaningfulness as a mechanism to achieve positive emotions and liveliness in their life; as expressed by one of the participants, "spirituality gives me solutions for many problems, gives me meaning in life" (F3.1F3).

Spirituality was seen as a source of positivity and meaningfulness in life, such as the following: "Life becomes perfect after entering in spirituality. Life becomes meaningful. We see each and every 
moment as a way for living life. Spirituality makes our emotions high. Spirituality brings purity in our thoughts" (Q320M). Spirituality also introduces some techniques that may give space to the human psyche to find meaning in their life, as revealed, for example, by this participant: "My life becomes meaningful due to the daily routine of this place" (Q124M). Some indicated that spirituality has the power to provide meaning in life through giving bigger goals, such as "to give meaning to life, inspiration to do something on Earth" (Q6F).

\subsubsection{Through Spiritual Techniques and Practices}

Most of the participants spoke about various techniques that they generally practiced to improve their self. One of the participants mentioned the use of prayer to solve his problems: "Whenever I come across a difficulty, I sit before the Universe, do some prayer, and ask to be shown the path; immediately I feel energetic and the problem is solved" (Q31F). Spiritual practices were seen as a tool to maintain mental homeostasis both in specific difficult situations and with daily stressors, as stated by one of the participants about the use of prayer: "In everyday life, when I am tired and I feel stress, I sit on my chair with closed eyes and think about everything, then how to manage everything, and I pray to God to help me. Then after a few moments, I open my eyes and feel very relaxed" (Q3F).

Most of the participants mentioned meditation as an important technique that they frequently use: "I follow spirituality by following meditation, chanting, morning prayer" (FG1.1F6). They practice it often on daily basis, as a part of their spiritual journey; for instance, some participants indicated it to be an effective tool to change their negative thoughts into positive ones: "Through spiritual life and belief in that, I get solutions for every problem in my life. Whenever I have a troubled situation like frustration, future anxiety, etc., I do meditation and, through that, I get the solution of my negative thoughts becoming positive and hopeful" (Q57M).

Some participants mentioned that they use a combination of methods to find the solution to their problem or to come out of a negative emotional state. For example, "When we prepare our daily routine, to visit in fresh air, exercise, practice pranayama and meditation, and we include our daily routine with Yajna, then spirituality influences life. All religions are the same, and belief in all religions influences our life" (Q99F). These methods were specifically used in stressful times to get some direction or solution from the problem: "I do believe in spirituality and meditation for at least 15 min daily. This removes daily minor and major stressors and problems of everyday life" (FG3.1M9). Some participants mentioned introspection as important method: “It's only the practice of introspection that I do, probably when I go to bed. I follow that before rising also; just being in my bed I go through introspection of myself on a daily basis" (FG2.1F1).

\subsection{Faith and Belief in the Sacred}

One of the frequently mentioned themes was that their faith in the sacred helped them to overcome difficult times, helped to maintain their positivity, and gave inner strength in day-to-day activities, for example, "Faith in God, that he directs everything. Belief that there is always another door when one closes. Positive thoughts that difficulties are given by God to teach us and improve us" (Q2F). A few of the participants mentioned that spirituality gives them confidence, such as, "Confidence comes in a person due to having belief in God and that he can do his work in a better way" (Q107M). Others mentioned that they receive guidance through dreams and intuitions, e.g., "Over the last few days I have had strange types of conflict in my mind. My mind is having some problems without any reason, even to the extent that I was fully broken. But I have deep faith in my Guruji who has given me guidance through dreams and, today, I have a new experience of life" (Q23F).

In the second category, participants mentioned situations in which they struggled with their own emotional or mental state (e.g., depression, negative mental state, hopelessness, loneliness) and faith in God or belief in the sacred helped them to feel secure and overcome those circumstances, for example, "In the 2nd semester, I was very depressed and negative. Belief in God and one's self is the only reason why I am here today and I am very happy now" or "when I dropped my education for one year 
because of my parents' disagreement about my education, I was very pessimistic and confused about my life. At that time only religious faith and personal belief helped me to overcome it" (Q112F).

\subsubsection{Attitude towards Life}

Some participants stated that spirituality provides a bigger framework for life, which in turn helps to get a better perspective to perceive stressors. Mentioning examples of different circumstances in their life, some participants explained that they have learnt to perceive things differently as a result of philosophy or books of spirituality. For instance, one participant mentioned that he perceived that whatever is happening in his life is for his good future: "I have done three-year coaching for medical; whenever I was not selected, the thought used to come to mind that whatever God does is always for our goodness and then I moved forward again with same determination" (Q27F). Participants showed an awareness that different perception or reasoning is required to survive in difficult circumstances, and that this can come through reading books, practicing meditation, and sometimes by listening to one's spiritual thought, e.g., "Whenever we are in a depression or feel sorrow for something, self-strength comes after listening to spiritual thoughts or reading spiritual books, which helps to escape from mind disturbances" (Q67M). Others looked up to spiritual leaders as examples to help them overcome difficult circumstances such as, "For the last 16 years I have had an asthma problem, and when I was in classes 10-11 I was completely on bedrest. But I did not lose my confidence and my faith in the belief that time would change, I would be alright, and I will be able to help others ( ... ). After tolerating a 16-year illness, I always feel that I have a lot of capacity. Guruji would want me to do something; this gives me strength" (Q25F).

\subsubsection{Difficulty on the Spiritual Path}

Participants often also mentioned 'feeling different' after following the spiritual path and not able to be completely accepted by people around them who do not have a spiritual perspective in their life. They mentioned that while their spirituality helped them to develop an identity and improved confidence, this difference that they have experienced has created some kind of difficulties too, as stated for example by one participant, "While telling the relevance and significance of true religiosity, meditation, chanting and yagna, and differences between spirituality and blind faith, I faced difficulties" (Q25F). Some participants spoke about the difficulty they were facing during interaction with persons who did not follow the spiritual path. They mentioned that when they try to introduce spiritual practices, it is difficult for them to convey the relevance of these practices to other people: "When I tried to make my neighbors understand that there is a need to escape from addictions and the importance of taking pure (raw and vegetarian) food, and also to make them understand about child marriage (bad social customs), then they made fun of me. Sometimes I get negative comments" (Q116M).

Some of the participants mentioned that due to following spiritual values, principles, philosophy, and practices in their day-to-day life, their life became different from those who are not following the same path, which can result in having to face disregard or humiliation from people. One participant said, "I am disrespected by society's people, I have to bear the humiliation, I have to walk alone" (Q93F). Nevertheless, participants asserted to be firm in their own path as mentioned, for instance, by one of the participants: "These types of beliefs create difficulties as well. For example, my parents chose the spiritual life, they are scolded badly and they have been blamed by neighbors, relatives and others. People stopped visiting and my parents had to listen to negative comments of others. But, we had faith that this is the first step of spirituality" (Q8F).

\subsection{Suicide}

Finally, participants were also asked their perspective about reasons of suicide among youth in India and how they could recognize a person who is either thinking about suicide or planning to suicide. 


\subsubsection{Reasons for Suicide}

Participants mentioned many reasons for youth suicide specifically in the Indian context, which were further divided into three domains: personal, social, and financial. Spiritual constructs such as lack of meaning in life, lack of goals, lack of self-knowledge, or exposure to positive practices during stressful times were mentioned as the major causes at a personal level. In reference to a case of suicide witnessed by a participant, she stated that the reason for suicide in that case was "[n]egative attitude towards life: his only way was to pass a medical exam, he had no other goal in life. If he thought there was another creative way to solve his problems he may not have done it" (FG1.1F7). Some participants specified that suicide is related to limited goals in an individual's life. Referring to one case where a boy killed himself due to failure in love, one of the participants said that the reason was that "he was limited in that he had a narrow goal, and only one goal (to get the girl)" (FG4.2M7).

At the social level, lack of support from family, no feeling of belongingness, orthodox systems of society, social disapproval, peer group pressure, or parents' expectation were mentioned frequently as the precursors for suicide. One participant iterated that the attempted suicide by a child was because "there was no one at home to support the child. Mummy and papa are working, they have no time for their children" (FG1.1F4). Fear linked to society was also cited as a major cause by participants: "I know a girl who became pregnant from [rape by] 3 boys and killed herself because of shame and the feeling of losing the prestige and respect of her family due to this" (FG3.2F2). At the economic level, lack of jobs, poverty, and lack of opportunity in workplace for growth were mentioned frequently. For example, referring to a farmer's case, one participant said that "a 28 year old man, a farmer, was in lot of trouble from the family and life. The family were constantly pressurizing him (probably for money) and he committed suicide"(FG3.2F1).

\subsubsection{Signs before Engaging in Suicidal Behavior}

Participants were asked about the warning signs displayed by the individual before they tried to take their lives. Most of the participants mentioned noticeable changes in an individual behavior before the attempt: " $(\ldots)$ ) they show loss of interest in their life, show lack of confidence and lack of social interaction, and lack of capacity to plan for future life" (FG1.2F4). Another participant stated that a "suicidal person always feels sad and will speak little to friends and family, always preferring to be alone" (FG1.2F6). Some participants mentioned that different people show different signs depending upon their age and role in the family. As revealed by one of the participants that "if someone who is smart person and educated person is suicidal then they wish to complete all their responsibilities, and will complete all his tasks as quickly as possible but look very stressed. Even if they laugh you can feel that he or she is sad" (FG1.2F10). It was noticed that participants frequently mentioned that indirect clues are more available then direct ones, such as, "the person will say there is nothing in my life and indirectly will ask about how to commit suicide and say pessimistic things that nothing is good in my life and life is worthless" (FG3.2F2). Sudden social withdrawal was also seen as strong clue: "he will stop mixing with others and not talk to anyone, he will stay alone" (FG3.2M10). Some participants observed that before an attempt an unusual behavior may provide a better clue then other conventional clues, as revealed by one of the participants who spoke about sudden social connectedness as a potential warning sign: "I agree with all, but it is possible that the person will talk to people he never spoke with before. My class competitor never spoke to me but in one exam he stood second and I secured first position. To my surprise he came to me and started talking in a very friendly manner. Next day when I went to his house, I came to know that he took pills to kill himself" (FG3.2M6). Some mentioned loss of faith and that negative thinking increases before suicide, as expressed by one participant: "they lose faith in themselves or have conflicts, no inner strengths and they develop negative attitudes" (FG1.1F9) or "he will always think in negative way, does not have positive attitude to life" (FG2.1F2). Some participants indicated loss of meaning in their life as an important warning sign, such as, "they say pessimistic things (like) that nothing is good in my life and feel that life is worthless" (FG3.2F3). 


\section{Discussion}

The responses of the participants revealed various important elements like self-knowledge, feelings of connectedness, formulas to redefine and find meaning in adversity, and having positive values and meaningfulness due to spirituality, which are recognized as strong protective factors against suicide (Colucci 2008, 2009a; Lenzi et al. 2012; Poll and Smith 2003). This section discusses the findings and highlights the possible mechanism through which spirituality works as a protective factor against suicidal behavior.

\subsection{Spirituality as Contributing to Wellbeing and Protective against Suicide}

Most of the participants indicated that their spiritual, religious, and personal beliefs contributed to their wellbeing in different ways, which worked as a buffer for suicidal behavior in adverse circumstances.

\subsection{Spirituality and Meaning in Life}

Most of the spiritual students in this study reported that their life was "very" or "extremely" meaningful and, for most of them, it was thanks to spiritual beliefs that they receive meaning in life. Also, in the open questions, most participants indicated that it is their spiritual, religious, and personal beliefs that give meaning to their lives. According to Wong and Fry (1998), meaning in life contributes to wellbeing and health, More specifically, perceived meaningfulness has been considered as a positive force in adolescents' lives, which in turn can work as buffer for suicide and other at-risk behaviors (Wright et al. 1993). Also, Frankl (1959) believed that a belief system may make life meaningful by giving man a purpose to achieve, rules to follow, rituals, and values, which in turn protect against harming oneself. Several other scholars have underlined the role of spirituality in contributing to existential wellbeing, including increasing self-esteem, auto-efficacy, and strength of will (Ellison 1993; Turner and Lloyd 1999). When it comes to mechanisms underlining the reinterpretation of difficult circumstances into meaningful events, religiosity and spirituality have been seen as the main source (Baumeister 1990).

Meaningfulness can be considered as the absence of hopelessness in an individual life. Abramason and colleagues highlighted a strong link between hopelessness and suicide among adolescents specifically during negative life events. In contrast, spirituality was perceived as providing a more positive attribution style during negative life circumstances (Fabricatore et al. 2000).

\subsection{Spirituality and Self}

Previous research indicates that spirituality and religion contribute to increased levels of self-control, self-monitoring, self-regulation (McCullough and Willoughby 2009), self-reflection (Brown and Ryan 2003), and self-development. These self-constructs have shown the potential to increase wellbeing. Participants frequently mentioned that spirituality increased self-reflection and monitoring in everyday life, which helped to understand oneself. They expressed that understanding the self helps to achieve the highest developed level of self, which is the ultimate aim of a spiritual seeker, suggesting the positive impact of meaningful self-rumination (Elliott and Coker 2008). Participants attributed prime importance to self-reflection in their daily life, which they believed they developed through spiritual practices. Self-reflection has previously shown positive links with happiness (Elliott and Coker 2008; Trapnell and Campbell 1999). Participants consistently mentioned their need to understand their self, find their potential, and ultimately achieve a developed self. The responses showed a possible mechanism of self-development. It is possible that spiritual practices first improve self-monitoring, which improves the observation of one's mental state and, in turn, may convert into meaningful self-rumination and self-growth and self-development, thereby gearing up the process of self-regulation (Carver and Scheier 2001). 


\subsection{Spirituality and Psychological Factors}

Spirituality seems to be particularly important in difficult moments of life (Koenig et al. 1992). In these circumstances, people receive support from their spiritual beliefs through coping strategies, religious and spiritual practices, feelings of a divine presence who gives support (Koenig et al. 1992), and by providing an understanding and sense to life's difficulties based on their beliefs (Pargament 1997). In our study, more than half of the sample answered "very much" or "an extreme amount" to the question, "To what extent do your spiritual, religious, and personal beliefs give you the strength to face difficulties?" More than 2/3 said that they found strength through their spiritual, religious, and personal beliefs. Negative life events and stressful experiences, which were reported by participants as being helped by religiousness and spirituality, include psychological problems, such as depression, anxiety, frustration, confusion, and anger; interpersonal difficulties, including loneliness, problems relating to other people, problems with their family, and coping with the illness or death of a relative; and, finally, other psychosocial difficulties might include problems with academic studies, and health problems, such as physical pain or illness.

Several participants reported the use of spiritual/religious coping strategies in difficult times. As previously also indicated by Koenig and collaborators (Koenig et al. 1992), some of them reported receiving help from divine support, being connected with a supreme God who gives them support and reassurance, and the feeling that they always have someone to trust and to follow in order to find solutions. Religious and spiritual practices include prayers, meditation, reading spiritual books, mantra, yoga, and other activities in the University, like classes of gita. Participants used various procedures for relaxing during stressful times, especially meditation and prayers. For others, thinking about a supreme being helps them find energy within.

Most participants affirmed that their spiritual beliefs help them to understand life's difficulties, which is consistent with previous literature (Pargament 1997). Some participants stated that, in their opinion, difficulties in life are given by God not as a punishment, but to make someone a better person by testing him or her. Perseverance through difficulties was seen as a value of personal growth, and a challenge to become stronger. In this way, they can face difficulties more peacefully instead of resorting to suicide, because they appear to have a purpose in their life. Previous research also indicated that several religious people believe that God knows human capacities and will not give a person more than what he or she can tolerate (Colucci and Martin 2008).

\subsection{Spirituality and Social Support}

Social isolation has been indicated as a strong precursor of suicide (Durkheim [1897] 1951; Van Orden et al. 2010). At the opposite, spirituality/religion may work as a protective factor through social support and expanding one's social network (Seybold and Hill 2001), for example, through the support of religious leaders (Musick et al. 2004), by being involved in a religious community (George et al. 2009), and performing altruistic behaviors (Oman et al. 1999). Also in our study, several participants believed that spirituality influences wellbeing and mental health through social support. They indicated that they receive direct social support from spiritual people like their guru and religious leader, teachers, relatives, and friends from the same religious community, or in an indirect way by being in a spiritual environment, like the university, and taking part in the religious community. Participants also indicated that their large social network helped them in difficult times, by offering support and advice, including when they felt depressed.

Some people in our sample indicated that their spiritual, religious, and personal beliefs give them a reason to work for others. In this regard, a large portion of the participants declared that to help others greatly contributes to their own wellbeing, as was previously found by Antonovsky (1980). Although this research suggests that there is a link between altruistic behavior and wellbeing, it is not clear if the sense of wellbeing while helping others is due to the increase of the social network or other factors, such as the self-esteem that arises in feeling useful for others which was mentioned by a 
few participants. This link should be further explored in future studies and potentially integrated in suicide prevention interventions.

\subsection{Spiritual/Religious Practices and Life Style}

According to the literature, spirituality also contributes to wellbeing and suicide prevention thorough spiritual/religious practices (Lenzi et al. 2012), which promote a health-oriented lifestyle (Troyer 1988). In support of Troyer's findings, several of the young people who took part in this research stated that their spiritual belief furnished them with a set of practices to follow in their everyday life; for instance, diets, practice of yoga and meditation, and other health-oriented activities helped them to avoid unhealthy behaviors. These spiritual practices may become a source for coping and support during difficult times (Johnson et al. 2005). Belief in power of spiritual practices can significantly improve one's wellbeing and reduce the risk of suicide (Broome and Broome 2007). Spiritual orientation can also work as protection against suicide attempts and may increase health and wellbeing (Garroutte et al. 2003).

\subsection{Spirituality and Positive Feelings}

Previous studies observed that spirituality also contributes to wellbeing through the positive feelings and emotions experienced as a direct influence of the spiritual beliefs, or indirectly through psychological and physiological changes initiated by spiritual practices (Larson et al. 1998). The former effect was also found in this study, where several participants observed that spirituality influences their lives by giving them energy and positive feelings. In fact, most participants indicated that their spiritual, religious, and personal beliefs were very or extremely important in helping them be optimistic and feel hopeful. Quite a few participants also affirmed that their spirituality gives them happiness, inner peace, stability, relief, inspiration, creativity, enthusiasm, determination, and positive thoughts. Even in difficult times, these positive feelings are important, as they help to make the situation bearable by promoting calmness, patience, peace, and positivity.

\subsection{Spirituality, Values, and Goals}

The roles of values and goals in life are considered potent contributors to happiness (Myers and Diener 1995). Results of the current study suggest that spirituality may work as a strong mediator for development of goal orientation and introduction and inculcation of various values in one's life. Most of the participants revealed that spirituality made their life goal-oriented and introduced important values. Awareness about goals and particular values, which can mediate the path towards the goal, was strongly linked with wellbeing. Goals are equated with the substance of the self (Carver and Scheier 2004). In past research on goal orientations, constitutive versus instrumental goal orientation were found to be linked differently to wellbeing (Fowers et al. 2010). Constitutive goal orientation was found to be strongly linked with wellbeing (Ryan and Deci 2001) but instrumental was found to be negatively associated with wellbeing (Kasser and Ryan 1996). Constitutive goals emphasize on process and activities to achieve goals. In the theoretical framework given by Fowers and collaborators (Fowers et al. 2010), constitutive goals focus on personal development. In the present study, students frequently mentioned the importance of development of self over other gains in life. Participants considered that materialistic goals, which are mostly instrumental/end-oriented in nature, were not important.

\subsection{Spirituality as a Source of Difficulties}

Some studies argue that spiritual/religious beliefs can be harmful, for instance, when they are used as negative coping strategies (Pargament 2002; Fitchett et al. 1999) or are misused for manipulation of believers (Larson and Larson 2003). In our study, spirituality was generally seen as having a positive impact on participants' feelings and lifestyle. However, when participants suggested some negative impacts, most of the potentially harmful aspects of spirituality and religion were due 
to misunderstanding and intolerance from people who did not share their same beliefs. Particularly, negative effects occurred within their own family when parents disagreed with the spiritual/religious choices made by their son or daughter.

In some instances, as a result of their strong sense of spirituality, participants reported feeling alone, different from others, or lonely in a society "that normally believes in other values" such as "materialism and selfishness." A few other participants affirmed having problems due to their spiritual beliefs when they have doubts about their faith, for instance, because no scientific theory can prove what they believe in. In these instances, their belief becomes the source of painful existential questions instead of generating positive feelings, as discussed above. The potentially isolating effects of holding a spiritual belief, and its negative impact on wellbeing, mental health, and suicidal behavior, requires further attention as previously argued (Colucci 2008).

\subsection{Limitations}

This study involved self-selected students in a spiritually oriented university and the results are not generalizable beyond this sample. To prevent social desirability and compliance of answers, the questionnaire was anonymous and collected in a group before being analyzed. Participants in focus groups were also given an anonymous form at the end of the session where they could add any comment including any issue they were unable or unwilling to discuss in the group. Qualitative research techniques such as triangulation and data saturation were implemented to improve research validity.

\section{Conclusions and Indications for Future Research and Suicide Prevention}

The 160 students who were part of a spiritual community and were actively involved in spiritual practices who took part in this research largely indicated that spirituality helps to give them a sense of meaning in their lives, even when they are in difficult situations, including when they feel psychologically unwell. They highlighted how spirituality is important to understanding oneself and to improving in their everyday and professional life through deep self-study. Most of the sample indicated that spirituality and/or religion gives them a way of life through rules and practices such as yoga and meditation. Approximately half of the sample reported getting comfort from their religious and spiritual beliefs, using spiritual or religious coping strategies in times of difficulties, and that they receive social support from a spiritual leader or from other people from their spiritual/religious community. Lastly, some participants commented that spirituality influences their wellbeing through giving positive feelings of hope and faith. All of these factors have previously been observed to be protective factors against suicidal behavior (Colucci and Martin 2008). Thus, this study contributes to the body of literature that indicates that spirituality and religion generally protect against suicide.

The potential harmful effect of spirituality suggested by a smaller body of literature was also investigated in our current study and mentioned by a few participants. However, this area requires further attention.

In conclusion, because of its generally positive link with wellbeing and positive emotions and coping strategies, spirituality/religion should be regularly included in an (holistic) approach to mental health and suicide prevention, instead of being generally neglected, as argued over a decade ago by Colucci (2008) and Colucci and Martin (2008). However, further research is needed to understand the role that spirituality (religious and not) plays in relation to suicidal behavior in multicultural contexts, as was also recommended in a recent suicide research agenda (Colucci et al. 2017).

Author Contributions: Conceptualization, E.C.; Methodology, E.C. and R.W., Formal Analysis, E.C. and R.W.; Investigation, E.C. and R.W.; Resources, E.C.; Data Curation, R.W.; Writing-Original Draft Preparation, E.C. and R.W.; Writing-Review and Editing, E.C. and R.W.; Funding Acquisition, E.C.". Other people, listed in acknowledgement, have contributed to different parts of this project. 
Acknowledgments: We are thankful to students and staff at DSVV for supporting and participating in this study. We would also like to express our gratitude to Manjula O'Connor for her intellectual and financial contribution to this study and Francesca de Giovanelli for her contribution to the data collection and preliminary analysis.

Conflicts of Interest: The authors declare no conflicts of interest.

\section{References}

Antonovsky, Aaron. 1980. Health, Stress and Coping. San Francisco: Jossey-Bass.

Barun, Virginia, and Victoria Clarke. 2006. Using Thematic Analysis in Psychology. Qualitative Research in Psychology 3: 77-101. [CrossRef]

Baumeister, Roy F. 1990. Suicide as escape from self. Psychological Review 97: 90. [CrossRef] [PubMed]

Berger, Peter L. 1967. The Sacred Canopy. New York: Guilford.

Berger, Peter L., and Thomas Luckmann. 1966. The Social Construction of Reality. New York: Anchor Books.

Blumer, Herbert. 1969. Symbolic Interactionism: Perspective and Method. Englewood Cliffs: Prentice Hall.

Broome, Barbara, and Rochelle Broome. 2007. Native Americans: Traditional healing. Urologic Nursing 27: 161-73. [PubMed]

Brown, Kirk Warren, and Richard M. Ryan. 2003. The benefits of being present: Mindfulness and its role in psychological wellbeing. Journal of Personality and Social Psychology 84: 822-48. [CrossRef] [PubMed]

Büssing, Arndt, Klaus Baumann, Niels Christian Hvidt, Harold G. Koenig, Christina M. Puchalski, and John Swinton. 2014. Special issue: Spirituality and Health. Evidence-Based Complementary and Alternative Medicine 2014: 682817. [CrossRef] [PubMed]

Campbell, Colin. 1999. Action as a will power. Sociological Review 47: 48-61. [CrossRef]

Carver, Charles S., and Michael F. Scheier. 2001. On the Self-Regulation of Behavior. New York: Cambridge University Press.

Carver, Charles S., and Michael F. Scheier. 2004. Self-regulation of action and affect. In Handbook of Self-Regulation: Research, Theory, and Applications. New York: Guilford Press, pp. 13-39.

Colucci, Erminia. 2007. "Focus groups can be fun": The use of activity-oriented questions in focus group discussions. Qualitative Health Journal 17: 1422-33. [CrossRef] [PubMed]

Colucci, Erminia. 2008. Recognizing spirituality in the assessment and prevention of suicidal behavior. World Cultural Psychiatry Research Review 3: 77-95.

Colucci, Erminia. 2009a. Cultural issues in suicide risk assessment. In Suicidal Behavior: Assessment of People-at-Risk. Edited by Updesh Kumar and Manas K. Mandal. New Delhi: SAGE, pp. 107-35.

Colucci, Erminia. 2009b. Haridwar: A Spiritual Journey. 6 min Film Documentary, India. Available online: https:/ / movie-ment.org/spirituality-and-spiritual-well-being-in-india / (accessed on 21 January 2018).

Colucci, Erminia, Tiffany Too, and Harry Minas. 2017. A Suicide Research Agenda for People from Immigrant and Refugee Backgrounds. Critical Suicidology Special issue, Death Studies. 41: 502-11. Available online: http:/ / www.tandfonline.com/doi/full/10.1080/07481187.2017.1332912?scroll=top\&needAccess=true (accessed on 31 May 2018). [CrossRef] [PubMed]

Colucci, Erminia, and David Lester. 2013. Suicide and Culture: Understanding the Context. Cambridge: Hogrefe Publishing.

Colucci, Erminia, and Graham Martin. 2008. Spirituality and religion along the suicidal path. Suicide and Life-Threatening Behaviour 38: 229-44. [CrossRef] [PubMed]

Creswell, John W. 2007. Data analysis and representation. In Qualitative Inquiry and Research Design: Choosing among Five Approaches, 2nd ed. Edited by John W. Creswell. Thousand Oaks: Sage, pp. 179-212.

Durkheim, Emile. 1951. Suicide: A Study in Sociology. New York: Free Press. First published 1897.

Elliott, Irina, and Suzanne Coker. 2008. Independent self-construal, self-reflection, and self-rumination: A path model for predicting happiness. Australian Journal of Psychology 60: 127-34. [CrossRef]

Ellison, Christopher G. 1993. Religious Involvement and Self-Perception among Black Americans. Social Forces 71: 1027-55. [CrossRef]

Erikson, Erik. H. 1963. Childhood and Society. New York: W. W. Norton. First published 1950.

Fabricatore, Anthony N., Paul J. Handal, and Mickey L. Fenzel. 2000. Personal spirituality as a moderator of the relationship between stressors and subjective wellbeing. Journal of Psychology and Theology 28: 221-28. [CrossRef] 
Fitchett, George, Bruce D. Rybarczyk, Gail A. DeMarco, and John J. Nicholas. 1999. The role of religion in medical rehabilitation outcomes: A longitudinal study. Rehabilitation Psychology 44: 333-53. [CrossRef]

Fowers, Blaine J., Christine O. Mollica, and Erin N. Procacci. 2010. Constitutive and instrumental goal orientations and their relations with eudaimonic and hedonic wellbeing. The Journal of Positive Psychology 5: 139-53. [CrossRef]

Frankl, Victor E. 1959. Man's Search for Meaning. New York: Washington Square Press.

Garroutte, Eva Marie, Jack Goldberg, Janette Beals, Richard Herrell, Spero M. Manson, and AI-SUPERPFP Team. 2003. Spirituality and attempted suicide among American Indians. Social Science E Medicine 56: 1571-79.

George, Linda K., Christopher G. Ellison, and David B. Larson. 2009. Explaining the Relationship between Religious Involvment and Health. Psychological Inquiry 13: 190-200. [CrossRef]

Hawks, S. 1994. Spiritual Health: Definition and theory. Wellness Perspectives 10: 3-13.

Hill, Peter C., and Eric M. Butter. 1995. The Role of Religion in Promoting Physical Health. Journal of Psychology and Christianity 14: 141-55.

Hill, Peter C., and Ralph W. Hood. 1999. Measures of Religiosity. Birmingham: Religious Education Press.

Hill, Peter C., Kenneth I. Pargament, Ralph W. Hood, Michael E. McCullough, James P. Swyers, David B. Larson, and Brian J. Zinnbauer. 2000. Conceptualizing religion and spirituality: Points of commonality, points of departure. Journal for the Theory of Social Behaviour 30: 51-77. [CrossRef]

Ho, Man Yee, Fanny M. Cheung, and Shu Fai Cheung. 2010. The role of meaning in life and optimism in promoting well-being. Personality and Individual Differences 48: 658-63. [CrossRef]

Hood, Ralph W., Peter C. Hill, and Bernard Spilka. 2009. The Psychology of Religion: An Empirical Approach. New York: Guilford Press.

House, James S., Karl R. Landis, and Debra Umberson. 1998. Social Relationship and Health. Science 241: 540-45. [CrossRef]

Idler, Ellen L., Marc A. Musick, Christopher G. Ellison, Linda K. George, Neal Krause, Marcia G. Ory, Kenneth I. Pargament, Lynda. H. Powell, Lynn G. Underwood, and David R. Williams. 2003. Measuring Multiple Dimension of Religion and Spirituality for Health Research. Research on Aging 25: 327-65. [CrossRef]

Johnson, Kimberly S., Katja I. Elbert-Avila, and James A. Tulsky. 2005. The influence of spiritual beliefs and practices on the treatment preferences of African Americans: A review of the literature. Journal of the American Geriatrics Society 53: 711-19. [CrossRef] [PubMed]

Kasser, Tim, and Richard M. Ryan. 1996. Further examining the American dream: Differential correlates of intrinsic and extrinsic goals. Personality and Social Psychology Bulletin 22: 280-87. [CrossRef]

King, Nigel. 2004. Using templates in the thematic analysis of text. In Essential Guide to Qualitative Methods in Organizational Research. Edited by Cassell Catherine and Symon Gillian. London: Sage, pp. 257-70.

King, Pamela Ebstyne, and Peter L. Benson. 2006. Spiritual development and adolescent wellbeing and thriving. In The Handbook of Spiritual Development in Childhood and Adolescence. Thousand Oaks: SAGE Publications, pp. 384-98.

Koenig, Harold G., Harvey J. Cohen, Dan G. Blazer, Carl Pieper, Keith G. Meador, Frank Shelp, Veeraindar Goli, and Bob DiPasquale. 1992. Religious coping and depression among elderly, hospitalized medically hill men. American Journal of Psychiatry 149: 1693-700. [PubMed]

Larson, David B., and Susan S. Larson. 2003. Spirituality's potential relevance to physical and emotional health: A brief review of quantitative research. Journal of Psychology and Theology 31: 37-51. [CrossRef]

Larson, David B., Patricia Sawyers, and Michael E. McCullough. 1998. Scientific Research on Spirituality and Health: A Report Based on the Scientific Progress in Spirituality Conferences. Rockville: National Institute for Healthcare Research.

Lenzi, Matteo, Erminia Colucci, and Harry Minas. 2012. Suicide, culture and society from a cross-national perspective. Cross-Cultural Research 46: 50-71. [CrossRef]

MacDonald, Douglas A. 2009. Identity and spirituality: Conventional and transpersonal perspectives. International Journal of Transpersonal Studies 28: 86-106. [CrossRef]

MacDonald, Douglas A., and Harris L. Friedman. 2009. Measures of spiritual and transpersonal constructs for use in yoga research. International Journal of Yoga 2: 2-12. [CrossRef] [PubMed]

Marsella, Anthony J. 1999. In search of meaning. Some thoughts on belief, doubt, and wellbeing. The International Journal of Transpersonal Studies 18: 41-52. 
McCullough, Michael E., and Brian L. Willoughby. 2009. Religion, self-regulation, and self-control: Associations, explanations, and implications. Psychological Bulletin 135: 69. [CrossRef] [PubMed]

Moreira-Almeida, Alexander, FranciscoLotufo Neto, and Harold G. Koenig. 2006. Religiousness and mental health: A review. Revista Brasileira de Psiquiatria 28: 242-50. [CrossRef] [PubMed]

Myers, David G., and Ed Diener. 1995. Who is happy? Psychological Science 6: 10-19. [CrossRef]

Musick Marc A., James S. House, and David R. Williams. 2004. Attendance at religious services and mortality in a national sample. Journal of Health and Social Behavior 45: 198-213. [CrossRef] [PubMed]

Oman, Doug, Carl E. Thoresen, and Kay McMahon. 1999. Volunteerism and mortality among the community-dwelling elderly. Journal of Health Psychology 4: 301-16. [CrossRef] [PubMed]

Pargament, Kenneth I. 1997. Theory, Research, Pratice. The Psychology of Religion and Coping. New York: Guilford.

Pargament, Kenneth I. 2002. The bitter and the sweet: An evaluation of the costs and benefits of religiousness. Psychological Inquiry 13: 168-81. [CrossRef]

Poll, Justin B., and Timothy B. Smith. 2003. The spiritual self: Toward a conceptualization of spiritual identity development. Journal of Psychology \& Theology 31: 129-42.

Rasic, Daniel T., Shay-Lee Belik, Brenda Elias, Laurence Y. Katz, Murray Enns, Jitender Sareen, and Swampy Cree Suicide Prevention Team. 2009. Spirituality, religion and suicidal behavior in a nationally representative sample. Journal of Affective Disorders 114: 32-40. [CrossRef]

Reker, Gary T. 1994. Logotheory and Logotherapy: Challenges, opportunities, and some empirical findings. International Forum for Logotherapy 17: 47-55.

Ryan, Richard M., and Edward L. Deci. 2000. Intrinsic and extrinsic motivations: Classic definitions and new directions. Contemporary Educational Psychology 25: 54-67. [CrossRef] [PubMed]

Ryan, Richard M., and Edward L. Deci. 2001. On happiness and human potentials: A review of research on hedonic and eudaimonic wellbeing. Annual Review of Psychology 52: 141-66. [CrossRef] [PubMed]

Seybold, Kevin S., and Peter C. Hill. 2001. The role of religion and spirituality in mental and physical health. Current Directions in Psychological Science 10: 21-24. [CrossRef]

Sheldon, Kennon M., Richard M. Ryan, Edward L. Deci, and Tim Kasser. 2004. The independent effects of goal contents and motives on wellbeing: It's both what you pursue and why you pursue it. Personality and Social Psychology Bulletin 30: 475-86. [CrossRef] [PubMed]

Trapnell, Paul D., and Jennifer D. Campbell. 1999. Private self-consciousness and the five-factor model of personality: Distinguishing rumination from reflection. Journal of Personality and Social Psychology 76: 284-304. [CrossRef] [PubMed]

Troyer, Henry. 1988. Review of cancer among 4 religious sects: Evidence that life-style are distinctive sets of risk factors. Social Science and Medicine 26: 1007-17. [CrossRef]

Turner, R. Jay, and Donald A. Lloyd. 1999. The Stress Process and the social Distribution of Depression. Journal of Health and Social Behavior 40: 721-41. [CrossRef]

Van Orden, Kimberly A., Tracy K. Witte, Kelly C. Cukrowicz, Scott R. Braithwaite, Edward A. Selby, and Thomas E. Joiner Jr. 2010. The interpersonal theory of suicide. Psychological Review 117: 575. [CrossRef] [PubMed]

WHOQOL SPRB Group. 2002a. WHOQOL Spirituality, Religiousness and Personal Beliefs (SRPB) Field-Test Instruments. Geneva: World Health Organization.

WHOQOL SPRB Group. 2002b. WHOQOL-SRPB Users Manual. Scoring and Coding for the WHOQOL-SRPB Field-Test Instruments. Geneva: World Health Organization.

Wong, Paul T. P., and Prem S. Fry. 1998. The Human Quest for Meaning. A Handbook of Psychological Research and Clinical Applications. Mahwah: Erlbaum.

Wright, Loyd S., Christopher J. Frost, and Stephen J. Wisecarver. 1993. Church attendance, meaningfulness of religion, and depressive symptomatology among adolescents. Journal of Youth and Adolescence 22: 559-68. [CrossRef]

(C) 2018 by the authors. Licensee MDPI, Basel, Switzerland. This article is an open access article distributed under the terms and conditions of the Creative Commons Attribution (CC BY) license (http:/ / creativecommons.org/licenses/by/4.0/). 